Available online at http://docs.lib.purdue.edu/jate

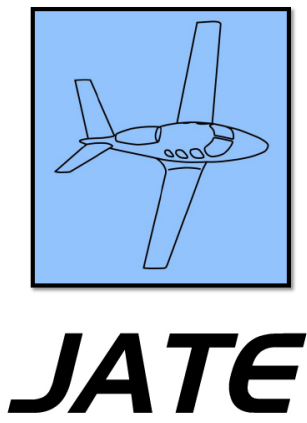

Journal of Aviation Technology and Engineering 7:1 (2017) 50-57

\title{
VFR-into-IMC Accident Trends: Perceptions of Deficiencies in Training
}

\author{
Wesley L. Major, Thomas Carney, Julius Keller, Allen Xie, and Matt Price
}

Purdue University

John Duncan

Kent State University

\author{
Lori Brown, Geoffrey R. Whitehurst, William G. Rantz, and Dominic Nicolai \\ Western Michigan University
}

Beth M. Beaudin-Seiler

Altarum Institute

\begin{abstract}
Pilots who operate under visual flight rules (VFR) and in visual meteorological conditions, who then continue flight into instrument meteorological conditions (IMC), remain as one of the leading causes of fatal aircraft accidents in general aviation. This paper examines past and current research initiatives, in seeking to identify causal factors and gaps in training that lead to VFR-into-IMC aircraft accidents, using a mixed methods approach. The Aircraft Owners and Pilots Association Air Safety Institute database and the National Transportation Safety Board database search engines were used to identify accident reports associated with VFR flight into IMC/deteriorating weather conditions for a 10-year time period (2003 to 2012). A national survey was also conducted to gain deeper insight into the self-identified training deficiencies of pilots. There is evidence that situational awareness is linked to decision-making, and there is a lack of proper training with regards to weather and weather technology concepts, making it difficult for pilots to gain these knowledge areas, skills, and abilities throughout their initial flight training and subsequent experience.
\end{abstract}

Keywords: VFR-into-IMC, general aviation, weather technology, aeronautical, decision-making, pilot training, situational awareness

\section{Introduction}

The actions of pilots who operate under visual flight rules (VFR) in visual meteorological conditions and then continue flight into instrument meteorological conditions (IMC) remain as some of the leading causes of fatal aircraft accidents

All correspondence concerning this article should be directed to Wesley L. Major at wmajor@purdue.edu. 
in general aviation (GA). According to the 24th Nall Report, in 2012 there were 50 weather-related accidents, of which 23 (46\%) involved continued visual flight into instrument conditions; 22 (95\%) of these accidents resulted in fatalities (Aircraft Owners and Pilots Association, 2015). This paper examines past and current research initiatives, seeking to identify causal factors and gaps in training that lead to VFRinto-IMC aircraft accidents, utilizing a mixed methods approach.

\section{Literature Review}

Numerous studies have attempted to identify links between situational awareness, flight experience, and aeronautical decision-making as they relate to continued VFR flight into instrument flight rules conditions (Goh \& Wiegmann, 2001; Goh \& Wiegmann, 2002; O'Hare \& Smitheram, 1995; Wiegmann, Goh, \& O'Hare, 2002; Wiggins \& O'Hare, 1995). Inaccurate weather data and situation assessment, overconfidence, prospect theory, and decision-making skills have all been examined as possible factors contributing to accidents related to continued operation into deteriorating weather conditions.

Goh and Wiegmann (2001) conducted research on pilots' decisions about whether to continue flight into IMC on a cross-country flight, in an attempt to identify decision-making influences. They highlighted situation assessment as a possible contributing factor, noting: "The importance of accurate situation assessment has been alluded to in studies that have found accurate diagnoses of problem situations are essential in good decision making" (Goh \& Wiegmann, 2001, p. 360). Additionally, Goh and Wiegmann (2001) observed that "pilots who chose to continue with the flight had higher ratings of skill and judgment" (p. 376). Perhaps these pilots had more confidence in their abilities to control the aircraft in adverse weather, even though the pilots who diverted identified the visibility levels more accurately than those who continued. "These findings suggest that pilots who continued VFR flight into IMC made errors early in the decisionmaking process in the form of inaccurate assessments of visibility" (Goh \& Wiegmann, 2001, p. 377).

Prospect theory is also considered a contributing factor in decision-making. O'Hare and Smitheram (1995) focused on prospect theory and found the way in which information was framed to pilots influenced their decision-making. Prospect theory postulates that if the pilot perceives the decision as a loss, the pilot may be more inclined to continue the flight to avoid losing out (on money, time, fuel) and accept more risk. On the other hand, if the decision is perceived as a gain (leading to lives saved/no damage to aircraft) versus a risky gain (possibility of arriving at the destination on time), the pilot may be more risk averse. Sunk cost bias is similar to prospect theory. It holds that pilots who have more invested in a venture will be more likely to continue, such as pressing on into deteriorating weather. However, Wiegmann et al. (2002) found results contradictory to sunk cost bias. In that study, pilots who encountered poor weather conditions earlier in the flight (when presumably less sunk costs existed) pressed on longer than those who encountered the conditions later in the flight.

Two common themes emerge from the literature on decision-making and continued visual flight into IMC. First, there is evidence that situational awareness is linked to decision-making, with time appearing to be a common factor (in terms of how long before a decision is made). Second, while there are multiple theories that provide a basis for decision prediction, there are also a number of variables involved, which tend to limit the predictability of these theories.

In addition to research conducted regarding pilot awareness and decision-making, a number of researchers (e.g., Ball, 2008; Blickensderfer et al., 2015; Knect, Ball \& Lenz, 2010a, 2010b; Wiggins \& O'Hare, 2003) have studied training regarding weather products and weather information in aviation. Whether it is the use of graphical weather displays, video weather training products utilizing web-based preflight weather briefings, in-cockpit NextGeneration Radar (NEXRAD) products, or computer-based training systems, these studies all provide findings suggesting that when properly trained with the systems, GA pilots show increased knowledge and superior performance in weather decision-making and show a higher tendency for strategic flying (i.e., planning, evaluating, anticipating) compared to purely tactical flying (i.e., reacting and responding to inflight conditions). Despite these advantages, these studies also have generally found that pilots rarely receive any formal training in the use of weather-related equipment and tools, and often lack the skills to apply weather knowledge to effective decision-making.

\section{Methodology}

An examination of aviation accident databases and a national survey were used to obtain a better understanding of the trends and perceived gaps in weather knowledge, skills, and abilities from the general aviation community.

\section{Accident Database}

The Aircraft Owners and Pilots Association (AOPA) Air Safety Institute (ASI) database and the National Transportation Safety Board (NTSB) database search engines were used to identify accident reports associated with VFR flight into IMC/deteriorating weather conditions for the period from 2003 to 2012. The initial screening of the databases identified 1,100 accidents occurring during IMC, for all circumstances. Each of the 1,100 IMC accidents was then reviewed to determine whether the specific accident was attributable to VFR flight into IMC/deteriorating weather conditions. From the coarse screening group of 1,100 IMC accidents, 319 accident cases were identified as 
VFR flight into IMC/deteriorating weather conditions occurrences. The scope for these identified accident reports consists of:

- Federal Aviation Regulations (FAR) Part 91: General Aviation Operations,

- airplanes,

- 10-year period (2003 through 2012), and

- VFR-into-IMC accidents occurring in the United States.

\section{Survey}

Because the survey research involved human subjects, the researchers obtained Institutional Review Board permission to conduct the study. The survey was created using Qualtrics, an online survey software package. AOPA, the Aviation Accreditation Board International (AABI), AvWeb, Halldale Group, the National Association of Flight Instructors (NAFI), the University Aviation Association (UAA), IMC Clubs of America, and the Society of Aviation and Flight Educators (SAFE) assisted in advertising the survey's web address through each organization's respective electronic newsletter. Handouts with the survey's web address were also distributed to attendees at the Experimental Aircraft Association (EAA) AirVenture 2014 in Oshkosh, Wisconsin, as well as distributed to relevant groups on social media such as LinkedIn.

\section{Results}

\section{Accident Database}

The initial keyword search of the ASI and NTSB databases for IMC accidents identified 1,100 accidents that occurred while operating in IMC for all circumstances during the period of interest. Each of the 1,100 IMC accidents was reviewed to determine whether the specific accident was attributable to VFR flight into IMC/deteriorating weather conditions. From this coarse screening, 319 accident cases were identified as VFR flight into IMC/ deteriorating weather conditions instances (Figure 1). The data reveal that the number of accidents associated with continued VFR flight into IMC/deteriorating conditions averaged 31.9 per year during the 10 -year period of study, with a minimum of 17 in 2012 and a maximum of 49 in 2004.

Figure 2 represents the severity of injuries occurring across the 319 VFR flight into IMC accidents identified in Figure 1. The injury severity types shown (Fatal, Serious. Minor/None) are as designated and defined by the NTSB (Notification and reporting of aircraft accidents or incidents, 49 C.F.R. $\$ 830,2016)$. The data reveal that approximately $87 \%$ of the accidents involving VFR flight into $\mathrm{IMC} /$ deteriorating conditions resulted in at least one fatality during the 10-year period of examination.

Accident data were also examined by pilot age. Figure 3 depicts the number of VFR-into-IMC accidents for each of the eight age groups that were partitioned from the 20032012 data. The data reveal that during the 10 -year period of study the top three age groups with the highest number of accidents were ages 60-69 (79 instances), ages 50-59 (69 instances), and ages 40-49 (68 instances). The average accident pilot age was 53.3, and the median age was 54.0. Figure 3 also presents the age distribution associated with VFR flight into IMC/deteriorating conditions, by percentage. The data show that during the 10 -year period of study the top three age groups, with the highest percentage of accidents, were ages 60-69 (25\%), ages 50-59 (22\%), and ages $40-49(21 \%)$. As a group, those pilots from

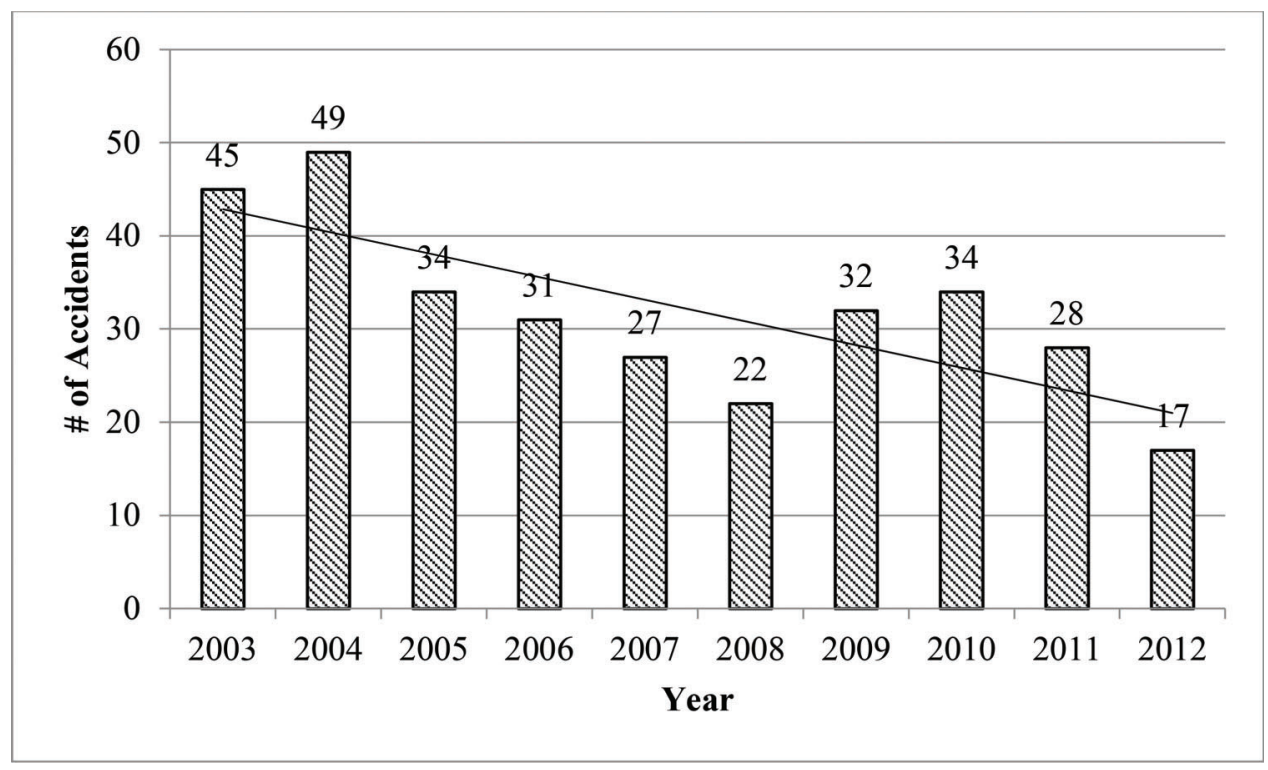

Figure 1. VFR-into-IMC accident trend for 2003 through 2012. 


\begin{tabular}{|l|c|c|}
\hline Injury Severity & Count & \% Total \\
\hline Fatal & 276 & 87 \\
\hline Serious & 10 & 3 \\
\hline Minor/None & 33 & 10 \\
\hline Total & 319 & 100 \\
\hline
\end{tabular}

Figure 2. Injury severity for accidents that were associated with VFR flight into IMC/deteriorating conditions for the 2003-2012 period.

\begin{tabular}{|l|c|c|}
\hline Age group & Count & Percentages \\
\hline$<20$ & 4 & $1 \%$ \\
\hline $20-29$ & 19 & $6 \%$ \\
\hline $30-39$ & 36 & $11 \%$ \\
\hline $40-49$ & 68 & $21 \%$ \\
\hline $50-59$ & 69 & $22 \%$ \\
\hline $60-69$ & 79 & $25 \%$ \\
\hline $70-79$ & 37 & $12 \%$ \\
\hline $80-89$ & 7 & $2 \%$ \\
\hline Total & 319 & $100 \%$ \\
\hline
\end{tabular}

Figure 3. Age distribution of pilot-in-command for accidents that were associated with VFR flight into IMC/deteriorating conditions for the 2003-2012 period.

\begin{tabular}{|c|c|}
\hline Total accidents & 319 \\
\hline Instrument rating & 104 \\
\hline No instrument rating & 215 \\
\hline \% No instrument rating & 67.4 \\
\hline \% Instrument rating & 32.6 \\
\hline
\end{tabular}

Figure 4. Instrument-rated pilots vs. non-instrument-rated pilots for accidents that were associated with VFR flight into IMC/deteriorating conditions for the 2003 through 2012 period.

age 40 to 69 were involved in $68 \%$ of all accidents during the 10-year period of study.

With respect to whether ratings and experience correlated with VFR-into-IMC accidents, Figure 4 depicts the percentage of accidents involving instrument-rated pilots, versus the percentage of accidents involving pilots without an instrument rating. The data reveal that during the 10 -year period of study, $67.4 \%$ of all accidents associated with continued VFR flight into IMC/deteriorating conditions involved pilots who did not have an instrument rating, while $32.6 \%$ involved pilots who possessed an instrument rating.

Figure 5 depicts the percentage of the total for the highest Federal Aviation Administration (FAA) pilot certificate held by each pilot-in-command for accidents that were associated with VFR flight into IMC/deteriorating conditions for the 2003 through 2012 period. The data reveal that during the 10 -year period of study, $74 \%$ of all pilots involved in accidents associated with continued VFR flight into IMC/deteriorating conditions had a Private Pilot certificate, $14 \%$ had a Commercial certificate, $8 \%$ had an Airline Transport Pilot certificate (ATP), 3\% had a Student

\begin{tabular}{|c|c|c|}
\hline Pilot certificate & $\#$ & $\mathbf{\%}$ \\
\hline None & 1 & 0.003 \\
\hline Student & 8 & 2.5 \\
\hline Sport & 3 & 0.01 \\
\hline Private & 237 & 74.3 \\
\hline Commercial & 44 & 13.8 \\
\hline ATP & 26 & 8.2 \\
\hline Total & 319 & \\
\hline
\end{tabular}

Figure 5. Pilot certification possessed by each pilot-in-command for accidents that were associated with VFR flight into IMC/deteriorating conditions for the 2003-2012 period.

\begin{tabular}{l|c|c}
\hline Range (hours) & \# of pilots & \% of pilots \\
\hline $0-250$ & 74 & 23.4 \\
\hline $250-500$ & 56 & 17.7 \\
\hline $500-1,000$ & 64 & 20.3 \\
\hline $1,000-2,000$ & 43 & 13.6 \\
\hline $2,000-5,000$ & 37 & 11.7 \\
\hline $5,000-10,000$ & 20 & 6.3 \\
\hline$>10,000$ & 22 & 7.0 \\
\hline Total & $3^{\text {a }}$ & \\
\hline \\
The pilot total number of flight hours was unknown/ \\
unreported for 3 cases.
\end{tabular}

Figure 6. Pilot total number of flight hours, by percentage, by each pilotin-command for accidents that were associated with VFR flight into IMC/ deteriorating conditions for the 2003-2012 period.

Pilot certificate, $1 \%$ had a Sport Pilot certificate, and $0.003 \%$ ( 1 person) had no pilot certification.

Figure 6 depicts the frequency distribution, by percentage, of the total number of flight hours for each pilot-incommand, for accidents that were associated with VFR flight into IMC/deteriorating conditions during the 20032012 period of study. The data reveal that during the 10-year period of study, $23.4 \%$ of all pilots involved in accidents associated with continued VFR flight into IMC/deteriorating conditions had 250 or less hours of total flight time, $17.7 \%$ had 250-500 hours of total flight time, $20.3 \%$ had $500-1,000$ hours of total flight time, $13.6 \%$ had 1,000-2,000 hours of total flight time, $11.7 \%$ had 2,000-5,000 hours of total flight time, $6.3 \%$ had 5,000-10,000 hours of total flight time, and $7.0 \%$ had more than 10,000 hours of total flight time.

\section{Survey}

A national survey of GA pilots was conducted online from May 15, 2014 through September 15, 2014. During that period, 1,047 surveys were started, with 675 of those completed by participants, for a total completion rate of 64\%. Response data were collected and analyzed using Qualtrics. The total survey consisted of 74 questions; however, only four questions are discussed in this paper, because the majority of the survey questions were related to pilots' use of cockpit weather information. It is noted that participants were able to skip questions and exit the survey without completion; these options resulted in some questions receiving more responses than others. 
Question composition included multiple choice, check all that apply, open-ended, and Likert scale. Some of the questions asked participants to provide additional information or explanation. In these cases, the researchers dispersed the qualitative responses into meaningful categories. The categories are provided for each question, including the number of responses for each category. For a number of the questions, categories such as "other" or "please explain" gave respondents additional opportunities to submit more detail and to provide subjective answers. The researchers have provided a listing and discussion of these additional details. The complete listing of survey questions, responses, and statistics can be found in Carney et al. (2015).

Question 6 asked participants, "How well did your education/training on aviation weather topics during your initial and/or subsequent flight training prepare you for 'real life' weather events?" Survey respondents' responses are summarized in Figure 7.

As noted in Figure 7, 366 (or just over 47\%) believe their education/training prepared them well or very well, while 121 (just under 16\%) believe their education/training prepared them poorly or very poorly to deal with "real life" weather events. It is important to recognize that Question 6 is highly subjective and the results reported here are based on each respondent's self-assessment of their training/ education and its effectiveness in preparing them for the flying they do.

Question 7 asked "Did you receive education/training on the proper use of observed and forecast aviation weather products available to pilots?" Respondents' answers to this question are reflected in the bar graph shown in Figure 8. Overwhelmingly (96\%), respondents answered the question affirmatively in regard to having received the training, but of that number, $21 \%$ felt their training in this area was inadequate, while a small percentage (4\%) reported not receiving any training.

Question 8 was posed to participants only if they felt their training was poor or inadequate, based on their response to Questions 6 and/or 7. Survey Question 8 asked the openended question "Based on what you have learned since your initial and/or subsequent flight training, what do you believe were the gaps in your weather education/training?" Responses were then categorized based on common themes. As the chart in Figure 9 shows, 191 respondents provided answers to this question. The most often-cited self-assessed gaps were "lack of knowledge/training" (28\%) and "lack of real world experience/transferring knowledge to the real world" (23\%).

Finally, Question 9 asked respondents, "Did you receive a review of the proper use of aviation weather information during your most recent Flight Review?" The bar graph shown in Figure 10 summarizes their responses. The responses to this question were almost evenly divided between those who had a review of their weather knowledge and those who did not receive a review in this area. In fact, more than half $(55 \%)$ either did not receive a review of weather or felt the review they received was inadequate.

\section{Discussion}

\section{Accident Database}

For the period 2003-2012, there were 319 accident cases identified as VFR flight into IMC/deteriorating weather conditions events. Even though there has been a decline in VFR-into-IMC accidents over the 10-year period of study (Figure 1), the data reveal how deadly this type of accident can be, with approximately $87 \%$ of those 319 accidents resulting in a fatality. The high fatal accident rate

\begin{tabular}{|l|c|c|c|c|c|c|c|}
\hline Question & $\begin{array}{c}\text { Very } \\
\text { well }\end{array}$ & Well & Adequately & Poorly & $\begin{array}{c}\text { Very } \\
\text { poorly }\end{array}$ & $\begin{array}{c}\text { Total } \\
\text { Responses }\end{array}$ & Mean \\
\hline $\begin{array}{l}\text { How well did } \\
\text { your } \\
\text { education/training } \\
\text { prepare you for } \\
\text { "real life" weather } \\
\text { events? }\end{array}$ & 145 & 221 & 289 & 102 & 19 & 776 & 2.52 \\
\hline
\end{tabular}

Figure 7. Qualtrics output for the survey question "How well did your education/training on aviation weather topics during your initial and/or subsequent flight training prepare you for 'real life' weather events?"

\begin{tabular}{|c|l|c|c|c|}
\hline$\#$ & Answer & Response & $\%$ \\
\hline 1 & Yes & 580 & $75 \%$ \\
2 & $\begin{array}{l}\text { Yes, but not } \\
\text { adequate }\end{array}$ & & 164 & $21 \%$ \\
\hline 3 & $\begin{array}{l}\text { education/training } \\
\text { No }\end{array}$ & 33 & $4 \%$ \\
\hline & Total & 777 & $100 \%$ \\
\hline
\end{tabular}

Figure 8. Qualtrics output for the survey question "Did you receive education/training on the proper use of observed and forecast aviation weather products available to pilots?" 
Q8. Based on what you have learned since your initial and/or subsequent flight training, what do you believe were the gaps in your weather education/training? (191)

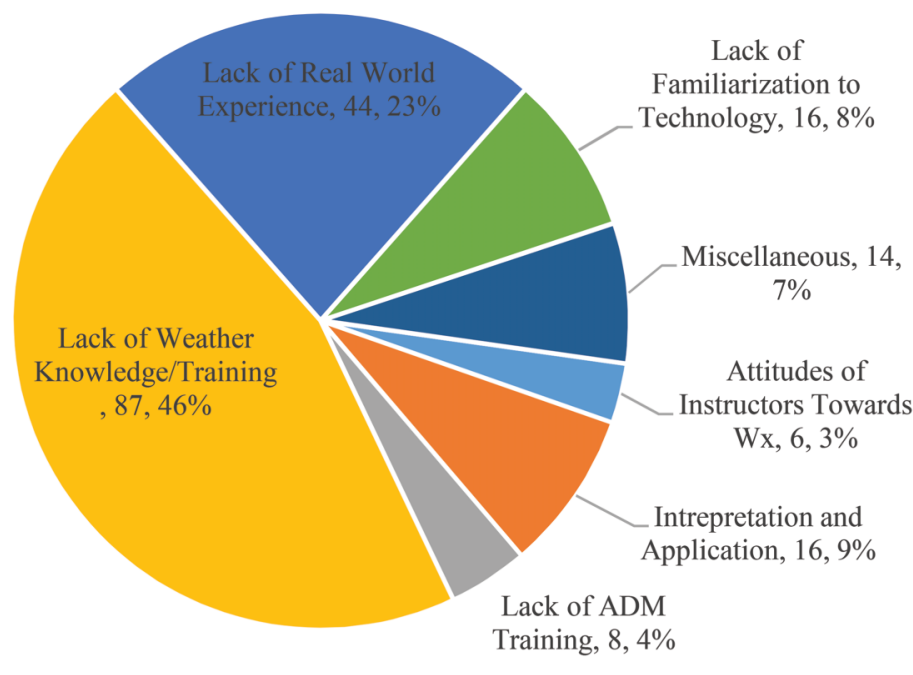

Figure 9. Qualtrics output for the survey question "Based on what you have learned since your initial and/or subsequent flight training, what do you believe were the gaps in your weather education/training?"

\begin{tabular}{|c|l|c|c|c|}
\hline$\#$ & Answer & & Response & $\%$ \\
\hline 1 & Yes & & 312 & $45 \%$ \\
2 & Yes, but was not & & 45 & $6 \%$ \\
3 & adequate & No & 343 & $49 \%$ \\
\hline & Total & 700 & $100 \%$ \\
\hline
\end{tabular}

Figure 10. Qualtrics output for the survey question "Did you receive a review of the proper use of aviation weather information during your most recent Flight Review?"

revealed by this study is in keeping with findings in AOPA's 24th Annual Nall Report (2015).

Goh and Wiegmann (2001) made note of overconfidence as a reason pilots find themselves in VFR-into-IMC situations, and cite pilots with higher flight time and more ratings as possible variables. However, the database information from the current research reveals that pilots with low total hours (fewer than 1,000) and holding a Private Pilot certificate account for two important variables associated with VFR-into-IMC accidents, demonstrating the effect of lack of experience on pilots' ability to accurately assess deteriorating weather situations.

\section{Survey}

Previous research suggests there is a gap identified in GA pilots being able to correlate, interpret, and apply weather information. The survey data allowed the researchers to gain insights into how GA pilots perceived the effectiveness of their flight training in preparing them for flight experiences related to weather phenomena and the use of weather technology in the cockpit.

While a large percentage of respondents received weather and weather technology training, roughly $20 \%$ stated their training was inadequate or it prepared them poorly for dealing with "real life" weather events. When asked about the gaps perceived in their weather education and training, respondents reported a variety of issues. These include a lack of information on how to use weather services/weather charts, lack of real world experience, lack of familiarization with weather technology/available online services, lack of ADM (aeronautical decisionmaking), and attitudes of instructors towards teaching their students weather-related topics, decision-making regarding weather, and its impact on their anticipated flights. A common theme was a lack of experience during training in various weather conditions, such as marginal visual flight rules and a training deficiency in the proper use of the multitude of weather technology tools available to pilots. Moreover, lack of instructor and student 
experience in crossing several weather systems during a cross-country flight, to recognize changing or deteriorating conditions, and lack of effective scenario-based training to aid in decision-making were also frequently cited. It is the instructor's discretion to decide what to teach regarding weather. One respondent stated, "It was taught as a necessary part to pass the test. [It was] Taught as a boring subject." These gaps self-identified by survey participants are congruent with literature and the inability to accurately utilize situational awareness relating to VFR-into-IMC situations.

More than half of the participants reported receiving either none or inadequate weather training during their most recent flight review. This requirement, formerly known as a Biennial Flight Review, requires the completion of a flight review every 24 months to act as pilot in command. In particular, 14 CFR 61.56 requires a minimum of one hour of flight training and one hour of ground training. The only specific requirement is a review of the current general operating and flight rules of 14 CFR Part 91 and, at the discretion of the person giving the flight review, those maneuvers and procedures necessary for the pilot to demonstrate the safe exercise of the privileges of their pilot certificate.

The application of VFR-into-IMC related weather knowledge was identified as a gap from the collected survey responses. While the Recreational pilot and private pilot knowledge test guide (FAA-G-8082-17) provided by the FAA (2015) outlines the breadth of weather topics to be taught and understood, the knowledge and skills are not being transferred to "real-world" application. GA pilots may be able to demonstrate knowledge during a checkride or written exam; however, if weather planning, weather data interpretation, and application of weather knowledge are not used consistently, those skills may be diminished or lost. Additionally, rote memory may be used to pass the written portion of the FAA exam. It is possible for students to pass the FAA written exam for a number of certificates and ratings, while answering incorrectly all questions pertaining to weather.

\section{Limitations}

Limitations of the survey include: participation was entirely voluntary and included only those persons who self-selected participation; no efforts to secure random selection of any type were made; and one age group (53-59) was inadvertently left off of the survey pilot demographicsthis may have skewed the results related to pilot age group of the respondents. Results are presented in separate questions, and thus may not be a reliable assessment of perceptions. Additionally, while the researchers believe that the size of the survey response gives confidence in the representativeness of the information gleaned to the GA pilot population in the United States, there is no assurance from the analysis that these results are strictly generalizable to the U.S. GA pilot population whose members conduct flight operations under the VFR of FAR Part 91.

\section{Conclusions}

Weaknesses in weather knowledge, understanding, correlation, and training have been well documented to possibly contribute to inadvertent VFR-into-IMC events. Even though VFR-into-IMC is a causative factor in only a small percentage of total aircraft accidents, a large proportion of those accidents result in fatalities.

This study examined accident databases, paired with a national survey conducted by the researchers to identify important related themes. Two common themes emerged from the literature and survey responses on decisionmaking and continued visual flight into IMC. First, there is evidence that a higher state of situational awareness is linked to effective decision-making, and there is limited training in actual weather conditions and/or with current weather technology aids for many VFR pilots, making it difficult for those pilots to gain weather knowledge, and weather data evaluation and decision-making skills, throughout their initial flight training and subsequent flying experiences. Second, while there are a number of theories that provide a basis for effective decisionmaking, there appear to be some important pilot attributes (e.g., total time, types of certificates and ratings, and risk tolerance) which tend to limit the applicability of these theories. Further studies in this area are needed, to fully understand the factors that lead pilots to encounter VFR-into-IMC accidents.

\section{References}

Aircraft Owners and Pilots Association. (2015). 24th Joseph T. Nall report: General aviation accidents in 2012. Retrieved from https:// www.aopa.org/-/media/files/aopa/home/pilot-resources/safety-andproficiency/accident-analysis/nall-report/15-fn-0022-1-24th-nall-v6. pdf

Ball, J. (2008). The impact of training on general aviation pilots' ability to make strategic weather-related decisions (DOT/FAA/AM-08/3). Oklahoma City, OK: Federal Aviation Administration.

Blickensderfer, E. A., Lanicci, J., Vincent, M., Thomas, R., Smith, M. J., \& Cruit, J. (2015). Training general aviation pilots for convective weather situations. Aerospace Medicine and Human Performance, 86(10), 881-888.

Carney, T., Brown, L., Duncan, J., Whitehurst, G., Rantz, W., Seiler, B., ... Mayes, P. (2015). Weather Technology in the Cockpit (WTIC) Project B: Unexpected transition from VFR to IMC (WTIC B Phase 1 Final Report).

Federal Aviation Administration. (2015). Recreational pilot and private pilot knowledge test guide (FAA-G-8082-17). Retrieved from http:// www.faa.gov/training_testing/testing/test_guides/media/faa-g-808217i.pdf

Goh, J., \& Wiegmann, D. A. (2001). Visual flight rules flight into instrument meteorological conditions: An empirical investigation of the possible causes. International Journal of Aviation Psychology, 11(4), 359-379. 
Goh, J., \& Wiegmann, D. A. (2002). Relating flight experience and pilots' perceptions of decision-making skill. Proceedings of the 46th Annual Meeting of the Human Factors and Ergonomics Society (pp. 81-85). Baltimore, MD: Human Factors and Ergonomics Society.

Knecht, W., Ball, J., \& Lenz, M. (2010a). Effects of video weather training products, web-based preflight weather briefing, and local versus nonlocal pilots on general aviation pilot weather knowledge and flight behavior. Phase I (DOT/FAA/AM-10/1). Oklahoma City, OK: Federal Aviation Administration.

Knecht, W., Ball, J., \& Lenz, M. (2010b). Effects of video weather training products, web-based preflight weather briefing, and local versus nonlocal pilots on general aviation pilot weather knowledge and flight behavior, Phase 2 (DOT/FAA/AM-10/6). Oklahoma City, OK: Federal Aviation Administration.
Notification and reporting of aircraft accidents or incidents and overdue aircraft, and preservation of aircraft wreckage, mail, cargo, and records. 49 C.F.R. $\$ 830$ (2016).

O'Hare, D., \& Smitheram, T. (1995). "Pressing on" into deteriorating conditions: An application of behavioral decision theory to pilot decision making. International Journal of Aviation Psychology, 5(4), 351-370.

Wiegmann, D. A., Goh, J., \& O'Hare, D. (2002). The role of situation assessment and flight experience in pilots' decisions to continue visual flight rules into adverse weather. Human Factors, 44(2), 189-197.

Wiggins, M., \& O'Hare, D. (1995). Expertise in aeronautical weatherrelated decision making: A cross-sectional analysis of general aviation pilots. Journal of Experimental Psychology: Applied, 1(4), 305-320.

Wiggins, M., \& O'Hare, D. (2003). Weatherwise: Evaluation of a cuebased training approach for the recognition of deteriorating weather conditions during flight. Human Factors, 45(2), 337-345. 